\title{
Eddy impacts on the Florida Current
}

\author{
E. Frajka-Williams, ${ }^{1}$ W. E. Johns,${ }^{2}$ C. S. Meinen, ${ }^{3}$ L. M. Beal, ${ }^{2}$ and S. A. Cunningham ${ }^{4}$ \\ Received 18 November 2012; revised 20 December 2012; accepted 23 December 2012; published 31 January 2013.
}

[1] The Gulf Stream in the Atlantic carries warm water northwards and forms both the return closure of the subtropical gyre as well as the upper limb of the meridional overturning circulation. Recent time series recorded east of the Bahamas at $26^{\circ} \mathrm{N}$ indicate that from May 2009 to April 2011 , in contrast with past observations, the northward flowing Antilles Current covaried with the Gulf Stream in the Florida Straits - the Florida Current - even though the Florida and Antilles Currents are separated by banks and islands spanning $150 \mathrm{~km}$. The peak-to-trough amplitude of transport variations during this period was $15 \times 10^{6} \mathrm{~m}^{3} \mathrm{~s}^{-1}$ for the Florida Current and $12 \times 10^{6} \mathrm{~m}^{3} \mathrm{~s}^{-1}$ for the Antilles Current, at time scales of 50 days to a year. From satellite observations, we show that the fluctuations in both the Florida and Antilles Currents between May 2009 and April 2011 are driven by eddy activity east of the Bahamas. Since the Florida Current time series is a critical time series for the state of the oceans, and often compared to climate models, this newly identified source of variability needs careful consideration when attributing the variability of the Florida Current to changes in the larger-scale circulations (e.g., gyre and overturning) or wind forcing. Citation: Frajka-Williams, E., W. E. Johns, C. S. Meinen, L. M. Beal, and S. A. Cunningham (2013), Eddy impacts on the Florida Current, Geophys. Res. Lett., 40, 349-353, doi:10.1002/grl.50115.

\section{Introduction}

[2] The Gulf Stream is the primary northward meridional flow in the top $1000 \mathrm{~m}$ of the North Atlantic, carrying warm subtropical waters to higher latitudes where they cool, giving off their heat to the atmosphere. As the western boundary intensification of the subtropical gyre, the strength of the Gulf Stream transport (measured in $10^{6} \mathrm{~m}^{3} \mathrm{~s}^{-1}=1 \mathrm{~Sv}$ ) depends on the basin-wide wind stress curl which forces the gyre circulation. However at $26^{\circ} \mathrm{N}$, where the Gulf Stream is confined between Florida and the Bahamas islands, the northward transport of the Gulf Stream - at this latitude, called the Florida Current (FC) - is nearly twice the southward thermocline flow (32 versus $18 \mathrm{~Sv})$. Due to

\footnotetext{
${ }^{1}$ National Oceanography Centre, University of Southampton Waterfront Campus, Southampton, UK

${ }^{2}$ Rosenstiel School of Marine and Atmospheric Science, University of Miami, Miami, Florida, USA.

${ }^{3}$ Atlantic Oceanographic and Meteorological Laboratory, Miami, Florida, USA.

${ }^{4}$ Scottish Association for Marine Science, Oban, UK.

Corresponding author: E. Frajka-Williams, National Oceanography Centre, University of Southampton Waterfront Campus, European Way, Southampton, SO14 3ZH, UK. (e.frajka-williams@noc.soton.ac.uk)

(C)2012. American Geophysical Union. All Rights Reserved. 0094-8276/13/10.1002/grl.50115
}

mass balance constraints, the remainder of the southward flow balancing the northward Florida Current as well as northward surface Ekman transport ( $3 \mathrm{~Sv}$ ) is found below $1000 \mathrm{~m}$ as the lower layer of the meridional overturning circulation (MOC, roughly $18 \mathrm{~Sv}$ ). By this simplificationwhere the sum of gyre flows and the overturning transport is equal to the northward FC transport-variations in FC transport may be associated either with variability of the horizontal gyre or the MOC.

[3] At $26^{\circ} \mathrm{N}$ in the Atlantic, an observational program has shown that the FC projects its variability directly onto the MOC, independently of other components [Kanzow et al., 2010]. A parallel investigation into ocean heat transport demonstrated that the transport of the MOC rather than the gyre dictates oceanic heat transport [Johns et al., 2011; Hall and Bryden, 1982]. These results highlight the significance of the MOC variability in the ocean's role in climate and reinforce the significance of the FC in MOC variability.

[4] Extensive investigations into the $\mathrm{FC}$ variability have been made from a cable time series of transport, available since 1982 (to follow). Fluctuations in the FC have been primarily associated with wind forcing, on a range of time scales. On short time scales up to 20 days (the "weather band") and at seasonal time scales, the FC is coherent with local winds [Schott et al., 1988; Atkinson et al., 2010; Rousset and Beal, 2011]. At seasonal time scales however, the annual cycle comprises only $10 \%$ of the variance [Meinen et al., 2010]. On interannual time scales (3-12 year time scales), variations can be attributed to changes in the large-scale wind forcing associated with the North Atlantic Oscillation [DiNezio et al., 2009, and references therein]. A particular gap in the coherence between the FC and wind stress was noted between 20 days and seasonal time scales [Schott et al., 1988] — a range of time scales associated with the mesoscale field in the ocean.

[5] The Antilles Current (AC), another western-intensified current in the Atlantic, is located on the other side of the Bahamas from the Florida Straits. In contrast to the FC, AC variability has been associated with the mesoscale eddy field [Gunn and Watts, 1982; Lee et al., 1996; Johns et al., 2008]. However, observations indicate that northward AC transport must supplement FC transport in order to balance the theoretical Sverdrup transport strength [Lee et al., 1996, and references therein]. Numerical simulations of ocean circulation suggest that the AC is part of the winddriven circulation: when an overturning circulation was present, the $\mathrm{AC}$ was stronger (than in a case with no overturning) and primarily contained gyre flow, while the FC carried the northward MOC transport [Johns et al., 2002]. While the AC and FC together may form the western boundary closure of the Atlantic subtropical gyre, previous calculations showed no statistical correlation between the AC and FC transports [Meinen et al., 2004], suggesting separate forcings of their variability. 
[6] Here, we present observational evidence from mid2009 to mid-2011, indicating that the FC transport fluctuations were correlated with those of the AC. We also show that during mid-2009 to mid-2011, both AC and FC variability were associated with mesoscale eddies east of the Bahamas, and discuss the implications for our understanding of Gulf Stream variability.

\section{Methods}

[7] Data were obtained from measurements in the Florida Straits and east of the Bahamas. The former data are from a submarine telephone cable which uses the principles of magnetic induction to deduce a transport estimate of the FC [Larsen and Sanford, 1985]. These observations have been made nearly continuously since 1982 and calibrated with frequent hydrographic measurements [Meinen et al., 2010]. The records are 3 day low-pass filtered, then provided on as a daily transport time series. Here, we used the data from April 2004 to April 2011 and linearly interpolated daily transport values over gaps in the record $(4.2 \%$ of the records from April 2004 to April 2011). Gaps of longer than 45 days are noted in the figures. These gaps in the record influence our ability to diagnose mesoscale variability at similar time scales to the gap duration.

[8] East of the Bahamas, the AC transport is estimated from current meters on taut-wire subsurface moorings (Figure 1a), as part of the RAPID-WATCH/MOCHA and WBTS programs (hereafter, $26^{\circ} \mathrm{N}$ array) [see Rayner et al., 2011]. Current meter records from April 2004 to April 2011 are used to estimate meridional transport of the AC in the top $1000 \mathrm{~m}$ between the coast of Abaco (about $77^{\circ} \mathrm{W}$ ) and a mooring $25 \mathrm{~km}$ offshore called $\mathrm{WB}_{2}\left(76.75^{\circ} \mathrm{W}\right)$. Details of data processing and transport calculations can be found in Johns et al. [2008]. While the core of the AC is between 200 and $800 \mathrm{~m}$ deep and northward, we have not removed transport above $200 \mathrm{~m}$ (which is occasionally southward) as it does not substantially change the variability. Here, we call the Antilles Current the integrated transport out to $76.75^{\circ} \mathrm{W}$ (Figure $1 \mathrm{~b}$ ) which is smaller than the total northward transport out to $\mathrm{WB}_{3}$ at $45 \mathrm{~km}$ offshore $\left(76.5^{\circ} \mathrm{W}\right)$, but the two estimates of transport are significantly correlated $(r=0.95)$. Using either $\mathrm{WB}_{2}$ or $\mathrm{WB}_{3}$ does not change the results (of a correlation between the $\mathrm{FC}$ and $\mathrm{AC}$ ); we use $\mathrm{WB}_{2}$ as it is easier to see the correlation by eye in the figures.

[9] Sea surface height (SSH) anomaly data were obtained from AVISO (information online at www.aviso.oceanobs. com). The data were used during the RAPID measurements from April 2004 to April 2011 and have a nominal resolution of $1 / 3^{\circ}$ in space and weekly in time. We use the DT-REF product: reference, delayed-time maps of sea level anomalies, with the raw data coming from TOPEX/Poseidon, Jason-1, ERS-2, and Envisat. While altimeter estimates of SSH are subject to degradation near coasts, previous results showed that SSH anomalies near the Bahamas agreed with dynamic height estimates from in situ moorings [Kanzow et al., 2010]. When a single time series is used (as in Figure 1b), it is the time series of SSH anomaly time series at $26.57^{\circ} \mathrm{N}$ and $76.67^{\circ} \mathrm{W}$, the grid point closest to the mooring used to define the outer edge of the Antilles Current, which is also the location where the SSH anomaly has the strongest correlation with the FC.
[10] During processing, the cable data were filtered with a 3 day low-pass filter, while the current meter records were filtered with a 2 day low-pass filter to remove tides, before calculating transports. Here, both Florida and Antilles Current transports were further filtered with a 7 day boxcar filter, then subsampled onto the weekly time grid for comparison to the SSH data. For visualization in Figure 1b, all three time series were additionally filtered with a 30 day low-pass Tukey filter. The FC transport time series (Figure 1b) was offset by $-30.4 \mathrm{~Sv}$ and $\mathrm{SSH}$ by $-3 \mathrm{~cm}$, to highlight covariability at the frequencies of interest during May 2009 to April 2011.

[11] While SSH anomaly data are available since 1992 and FC transport data since 1982, we will focus primarily on the period from 2004 to 2011, when all three data sources are available.

\section{Results}

[12] Over April 2004 to April 2011, the transports of the $\mathrm{FC}$ and $\mathrm{AC}$ were $31.6 \pm 3.1 \mathrm{~Sv}$ (mean $\pm \mathrm{std}$ ) and $1.2 \pm 2.5 \mathrm{~Sv}$, respectively (Figure 1b). From May 2009 to April 2011, transport anomalies were correlated with zero lag (Figure 2a). In particular, the maximum correlation was $r=0.66(99 \%$ significance) at zero lag. In contrast, there was an insignificant correlation for the period from April 2004 to April $2009(r=0.04)$. During the latter period, the peak-to-trough fluctuations in transport were $15.4 \mathrm{~Sv}$ for the FC and $11.7 \mathrm{~Sv}$ for the AC. In general, when the FC was $3 \mathrm{~Sv}$ stronger northward, the AC was $3 \mathrm{~Sv}$ stronger than its mean. Because the transport time series varied in phase, the net northward fluctuations of their combined transports were greater than transport variations in either individual record. While the period under consideration is short (roughly 2 years), a linear relationship between the AC and FC transports explained more than $43 \%$ of the variance of the FC transports from May 2009 to April 2011.

[13] Since the AC has previously been associated with the mesoscale eddy field, SSH anomalies at a point east of the Bahamas $\left(76.67^{\circ} \mathrm{W}\right.$ and $\left.26.5^{\circ} \mathrm{N}\right)$ were compared to the $\mathrm{AC}$ transport anomalies and found to correlate for the whole duration of the record, 2004-2011 $(r=0.71,99 \%$ significance). In particular, low values of AC transport are related to negative SSH anomalies (depressions), while high values were associated with positive anomalies (elevations). To determine the spatial structure of the SSH anomalies responsible for the fluctuations in the $\mathrm{AC}$, we calculated maps of the regression slope between the AC transport and SSH anomalies. At zero lag (Figure 3c), the regression map highlights a closed region in the SSH anomalies, with an area of significance $200-300 \mathrm{~km}$ diameter. This means that when the SSH is higher east of the Bahamas, it is higher not just at a single location, but is associated with an anticyclonic eddy (circulation in the clockwise sense) with northward flow adjacent to the Bahamas. The lagged regression maps for SSH anomalies preceding AC transport anomalies (Figures $3 a$ and $3 b$ ) further show that these anomalies originated east of the coast, in line with the westward propagating anomalies highlighted in Kanzow et al. [2009]. This is relevant because it shows that the anomalies in SSH, AC, and FC measures were preceded by an open-ocean anomaly in sea surface height, rather than locally forced by winds or other processes. At the Bahamas, as a consequence of 

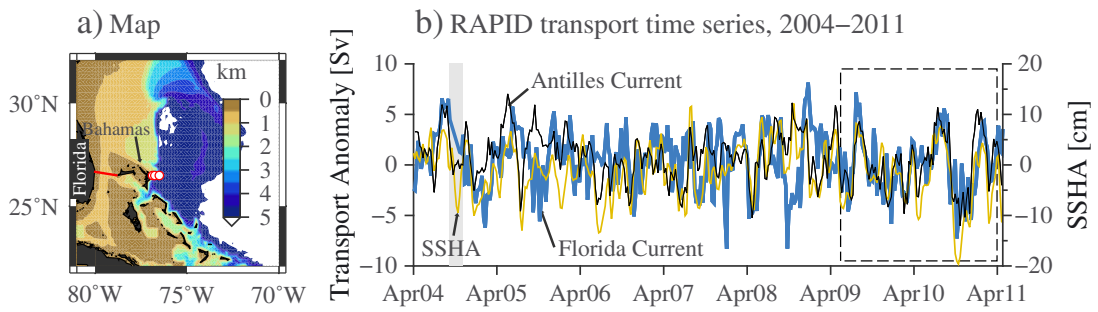

Figure 1. (a) Map of the region with land in black and bathymetry shaded at $500 \mathrm{~m}$ intervals. Moorings used to estimate the $\mathrm{AC}$ transport are given by the red open circles, $\mathrm{WB}_{2}$ and $\mathrm{WB}_{3}$ at $76.75^{\circ} \mathrm{W}$ and $76.5^{\circ} \mathrm{W}$, respectively, and $26.5^{\circ} \mathrm{N}$. Additional moorings used are between $\mathrm{WB}_{2}$ and the Bahamas and are indistinguishable at this scale. The SSH anomaly time series at $76.67^{\circ} \mathrm{W}$ and $26.5^{\circ} \mathrm{N}$ are between the centers of the two visible white dots. The FC cable position is given by the red line between Florida and the Bahamas islands. (b) Florida Current (thick blue) and Antilles Current transport anomalies (thin black) for the period April 2004 to April 2011, with amplitudes on the left $y$ axis. Also plotted are SSH anomalies at $26.57^{\circ} \mathrm{N}, 76.67^{\circ} \mathrm{W}$, with the seasonal cycle removed (yellow). The roughly 2 month period from September to October 2004 is shaded in grey indicating a gap in the FC cable data. The box (black, dashed) shows the period where the FC and $\mathrm{AC}$ are correlated.

the presence of this eddy, the measured AC transport is stronger, since the current meter observations are in the northward part of the eddy (between about $77^{\circ} \mathrm{W}$ and $\left.75^{\circ} \mathrm{W}\right)$. Similarly, when the SSH is lower, as associated with a cyclonic eddy, southward flow is adjacent to the Bahamas and the measured $\mathrm{AC}$ is weaker and occasionally reversed.

[14] While the AC transport fluctuations are correlated with SSH anomaly time series for the duration of the $\mathrm{AC}$ records, the $\mathrm{AC}$ and $\mathrm{FC}$ time series were only correlated from May 2009 to April 2011. To investigate the relationship between the SSH anomalies and FC transport during the RAPID period and in this shorter period of AC-FC correlation, we calculate the coherence and phase between the $\mathrm{FC}$ transport time series and SSH anomalies (Figures $2 \mathrm{~b}$ and 2c). High coherence is present in the band from about 50 to 150 days (Figure 2a). While the 2009-2011 period shows higher coherence in this band, the longer 20042011 period also shows relatively high coherence in this band even though the overall correlation for the longer period is almost zero. The phase offset is less than 7 days, with the SSH anomalies leading the FC transport anomalies
(Figure 2c). While the lag appears to be longer than in the case of the $\mathrm{FC}$ and $\mathrm{AC}$ lag correlations, between the filtering applied during processing of the FC and $\mathrm{AC}$ and the actual repeat timing of satellite altimeters used to create the $\mathrm{SSH}$ product, time variations on time scales shorter than 7 days cannot be resolved. The coherence indicates that while there was some coherence in the period 2004-2009 between the FC transports and $\mathrm{SSH}$ anomalies, it is much greater $\left(\gamma^{2}>0.6\right)$ during the later time, May 2009 to April 2011, at around 100 day time scale. In turn, it could be inferred that the impact of these mesoscale features on both the AC and FC is larger during this period and would stand out more clearly with respect to other processes that could drive transport fluctuations of FC.

\section{Discussion}

[15] While the SSH anomalies are consistent with transport estimates of the $\mathrm{AC}$, they do not immediately explain the covariability with the Florida Current or the nonstationarity of the covariability. During May 2009 to April
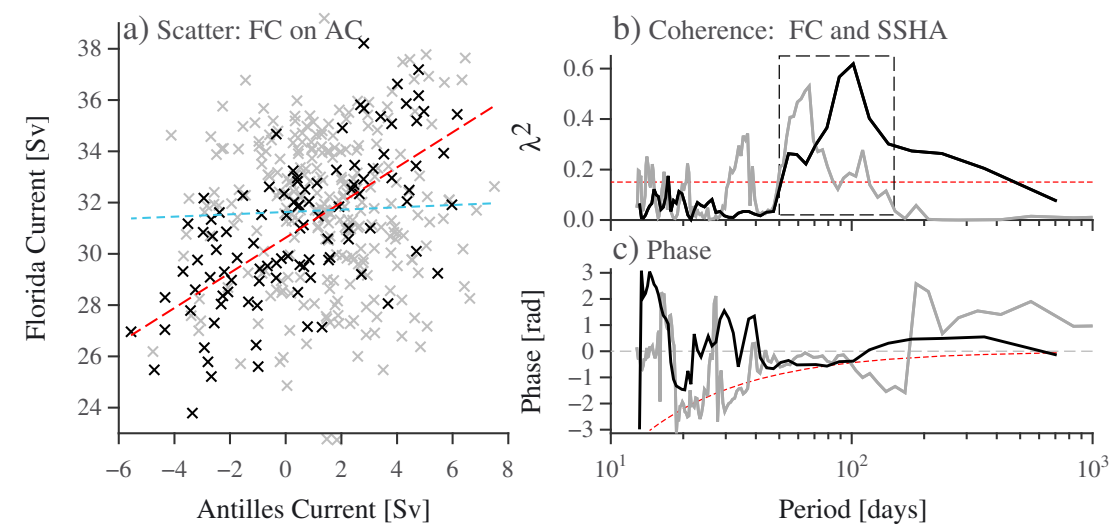

Figure 2. (a) Scatter plot of transport time series for the FC and AC, for April 2004 to April 2009 (grey) and May 2009 to April 2011 (black), with the best fit regression lines in blue and red, respectively, and correlation coefficients $r=0.04$ (not significant) and $r=0.66$ (99\% significant), respectively. (b) Magnitude squared coherence between the FC transport and the SSH anomaly time series, for the same periods, and colors as in Figure $2 \mathrm{a}$. Areas above the red, dashed curve are significant. The box (dashed black) indicates the mesoscale timescales (50-150 days). (c) Phase in radians, where a 7 day lag (SSH leading) is in dashed red. 


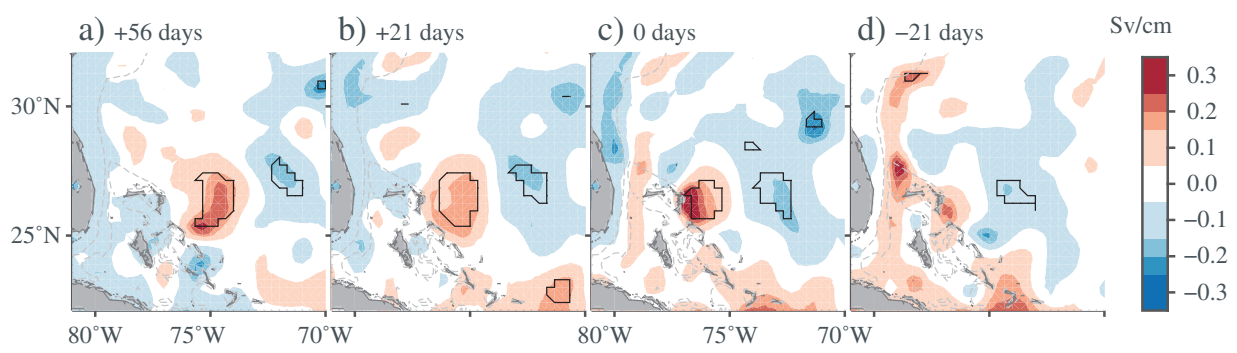

Figure 3. Lagged regression maps between the AC transport and SSH anomalies for the time period May 2009 to April 2011, where the SSH time series has had its seasonal cycle removed. The slope of the regression is plotted in color for lags of (a) 56, (b) 21, (c) 0, and (d) -21 days. Positive lags indicate that the SSH anomalies precede the AC transport anomalies. Significant regions at the $95 \%$ level are contoured in black. The $800 \mathrm{~m}$ bathymetric contour is also contoured with dashed grey.

2011, there appeared to be larger amplitude elevations and depressions in the SSH anomalies east of the Bahamas than prior to it (April 2004 to April 2009). This is shown in Figure 4, where the RMS amplitudes of sea surface height anomaly are averaged for the two periods: April 2004 to April 2009 and May 2009 to April 2011. While the first period is of longer duration than the latter, the results are not sensitive to this choice. For any 2 year period between April 2004 and April 2009, the maximum RMS amplitude of SSH anomaly between $74-76^{\circ} \mathrm{W}$ was $12.6 \mathrm{~cm}$, while for May 2009 to April 2011, it was $15.6 \mathrm{~cm}$. This suggests that the eddies east of the Bahamas, associated with the anomalies in the SSH time series, had larger amplitude than previously.

[16] In an idealized analytical and numerical study, Simmons and Nof [2002] simulated an encounter between an anticyclone and a gap in a meridional wall. Their results indicate that when intense eddies encounter gaps, they are drained by wall jets on either side of the gap (east and west) until the eddy can squeeze through the gap. The lagged regression between $\mathrm{SSH}$ anomalies and $\mathrm{AC}$ transports in Figure 3 was extended in time, to see how SSH anomalies change following the $\mathrm{AC}$ transport anomalies. At 21 days past $\mathrm{AC}$ variations, we found that the eddy at the Bahamas had shrunk and moved closer to - and partially throughthe gap, although significance is reduced. In addition, both at zero lag and 21 days lag, elongated anomalies in the regression slope are found west of the Bahamas, aligned with the Florida Straits (Figure 3d), suggestive of the wall jets in Simmons and Nof [2002]. However, in the observations,

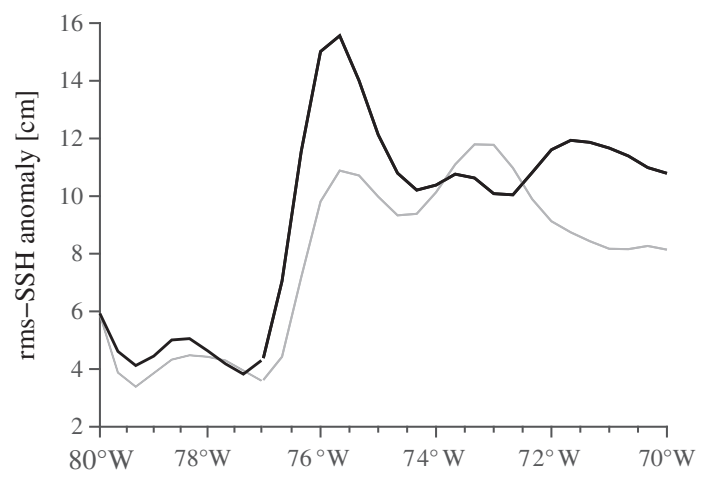

Figure 4. Root mean square amplitude of SSH anomalies along $26.58^{\circ} \mathrm{N}$ for the intervals April 2004 to April 2009 (solid grey line) and May 2009 to April 2011 (solid black line), as in Kanzow et al. [2009, Figure 6]. both cyclones and anticyclones were encountered the Bahamas and were associated with a response in the Florida Current. The real ocean has more complicated topography (Figure 1a) than the simple meridional wall of Simmons and Nof [2002]. As well, the gap itself is a narrow zonal channel some $150 \mathrm{~km}$ long, and while the water is full depth $(4000 \mathrm{~m})$ east of the gap, west of the gap it is less than $1000 \mathrm{~m}$ deep. While results are qualitatively promising, there are substantial differences between the idealized model and observations presented here.

\section{Conclusions}

[17] In contrast to previous studies, the FC and AC transport time series were shown to be correlated from May 2009 to April 2011. Coincident with the fluctuations in the AC and FC transports, closed contours of SSH anomalies east of the Bahamas were identified, with diameters of roughly $200-300 \mathrm{~km}$ and amplitudes of $\pm 15 \mathrm{~cm}$. These results indicate that the fluctuations in the AC are governed by mesoscale eddy activity east of the Bahamas, where the SSH anomalies and in situ instruments were located, consistent with previous research [e.g., Lee et al., 1996]. While the AC transport appears to be controlled by the eddy activity throughout the record, 2004-2011, the FC variability was most clearly influenced by the eddies from May 2009 to April 2011. During this 2009-2011 period, the fluctuations in the AC transport west of $76.75^{\circ} \mathrm{W}$ were equal in magnitude to the fluctuations in the $\mathrm{FC}$ transport. If the $\mathrm{AC}$ were considered to be part of the western boundary current, as suggested by Thomas et al. [2012], then the combined fluctuations of the AC and FC in 2009-2011 would double in range relative to considering the $\mathrm{FC}$ alone.

[18] Lagged regression maps between the AC and SSH anomalies further show that the SSH anomalies responsible for AC transport anomalies originated east of the Bahamas, although significance is reduced with distance offshore (Figures 3a-3c). These are consistent with observations from all ocean basins of mesoscale eddies and waves propagating westward. Here, this result supports the idea that these eddies can be an important, or sometimes even dominant, source of variability for both the FC and AC in addition to their forced response to local and regional winds.

[19] As the Gulf Stream is a major artery of the global ocean circulation, and transport estimates in the Florida Straits are one of the longest, high-temporal resolution time series of a western boundary current, understanding the 
sources of variability of the Gulf Stream is important. The cable observations are regularly used to validate numerical models, or are compared with climate indices to improve our understanding of the ocean-atmosphere system. Particularly when most climate models do not include the mesoscale physical processes we expect here, this new source of variability may inform our interpretation of agreement or disagreement between observations and models. Even in models which resolve eddies, these eddy impacts would not be expected to occur at the same times as in the real ocean, due to the stochastic nature of eddies.

[20] While the simple relationship $(\mathrm{FC}=$ gyre $+\mathrm{MOC})$ and past results from observations of the MOC [Kanzow et al., 2010] suggested that the Gulf Stream variability should project onto large-scale circulations, we have shown that some FC variations reflect local, stochastic, and internal ocean forcing by mesoscale eddies from the Atlantic. The transmission of eddy variability through the Bahamas Banks from the Antilles to Florida Currents presents a new source of variability to the FC not previously explored. Indeed, without the array east of the Bahamas, relating the transport variability of the FC and AC would not be possible.

[21] Acknowledgments. Data from the RAPID-WATCH/MOCHA project are funded by the Natural Environment Research Council (NERC) and National Science Foundation (NSF) and are freely available from www.noc.soton.ac.uk/rapidmoc. Florida Current transports estimates are funded by the National Oceanic and Atmospheric Administration (NOAA) and are available from www.aoml.noaa.gov/phod/floridacurrent. The altimeter products were produced by Ssalto/Duacs and distributed by Aviso, with support from Cnes (http://www.aviso.oceanobs.com/duacs/). Many thanks to A. Houk for reprocessing archived data from the moorings off of the Bahamas. The authors would like to thank J. Baehr, H. Bryden, A. Duchez, J. Hirschi, and J. Lilly for helpful discussions and special thanks to the captain, crew and science parties involved in the hydrographic section data and mooring deployments and recovery.

\section{References}

Atkinson, C. P., H. L. Bryden, J. J.-M. Hirschi, and T. Kanzow (2010), On the seasonal cycles and variability of Florida Straits, Ekman and Sverdrup transports at $26^{\circ} \mathrm{N}$ in the Atlantic Ocean, Ocean Sci., 6, 837-859.
DiNezio, P. N., L. J. Gramer, W. E. Johns, C. S. Meinen, and M. O. Baringer (2009), Observed interannual variability of the Florida Current: Wind forcing and the North Atlantic Oscillation, J. Phys. Oceanogr., $39,721-736$.

Gunn, J. T., and D. R. Watts (1982), On the currents and water masses north of the Antilles/Bahamas arc, J. Mar. Res., 40, 1-18.

Hall, M. M., and H. L. Bryden (1982), Direct estimates and mechanisms of ocean heat transport, Deep Sea Res., 29, 339-359.

Johns, W. E., et al. (2011), Continuous, array-based estimates of Atlantic Ocean heat transport at $26.5^{\circ} \mathrm{N}, J$. Climate, $24,2429-2449$.

Johns, W. E., L. M. Beal, M. O. Baringer, J. R. Molina, S. A. Cunningham, T. Kanzow, and D. Rayner (2008), Variability of shallow and deep western boundary currents off the Bahamas during 2004-05: Results from the $26^{\circ} \mathrm{N}$ RAPID-MOC array, J. Phys. Oceanogr., 38, 605-623.

Johns, W. E., T. L. Townsend, D. M. Fratantoni, and W. D. Wilson (2002), On the Atlantic inflow to the Caribbean Sea, Deep Sea Res. I, $49,211-243$

Kanzow, T., H. L. Johnson, D. P. Marshall, S. A. Cunningham, J. J.-M. Hirschi, A. Mujahid, H. L. Bryden, and W. E. Johns (2009), Basinwide integrated volume transports in an eddy-filled ocean, J. Phys. Oceanogr., 39, 3091-3110.

Kanzow, T., et al. (2010), Seasonal variability of the Atlantic meridional overturning circulation at $26.5^{\circ} \mathrm{N}, \mathrm{J}$. Climate, $23,5678-5698$.

Larsen, J. C., and T. B. Sanford (1985), Florida Current volume transport from voltage measurements, Science, 227, 302-304.

Lee, T. N., W. E. Johns, R. J. Zantopp, and E. R. Fillenbaum (1996), Moored observations of western boundary current variability and thermohaline circulation at $26.5^{\circ} \mathrm{N}$ in the subtropical North Atlantic, J. Phys. Oceanogr., 26, 962-983.

Meinen, C. S., M. O. Baringer, and R. F. Garcia (2010), Florida Current transport variability: An analysis of annual and longer-period signals, Deep Sea Res., 57, 835-846.

Meinen, C. S., S. L. Garzoli, W. E. Johns, and M. O. Baringer (2004), Transport variability of the deep western boundary current and the Antilles Current off Abaco Island, Bahamas, Deep Sea Res., 51, 1397-1415.

Rayner, D., et al. (2011), Monitoring the Atlantic meridional overturning circulation, Deep Sea Res. II, 58, 1744-1753.

Rousset, C., and L. M. Beal (2011), On the seasonal variability of the currents in the Straits of Florida and Yucatan Channel, J. Geophys. Res., 116, C08004.

Schott, F. A., T. N. Lee, and R. Zantopp (1988), Variability of structure and transport of the Florida Current in the period range of days to seasonal, J. Phys. Oceanogr., 18, 1209-1230.

Simmons, H. L., and D. Nof (2002), The squeezing of eddies through gaps, J. Phys. Oceanogr., 32, 314-335.

Thomas, M. D., A. M. Boer de, D. P. Stevens, and H. L. Johnson (2012), Upper ocean manifestations of a reducing meridional overturning circulation, Geophys. Res. Lett., 39, L16609. 